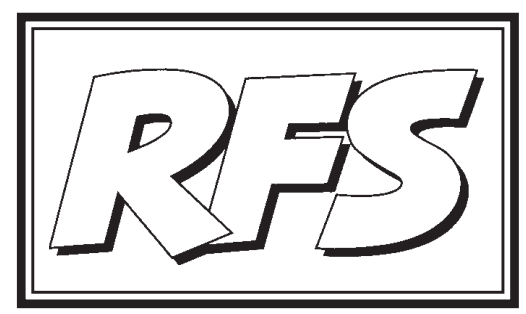

Revista de Fomento Social, 59 (2004), 11-12

\title{
Dos días de marzo
}

Por motivos diferentes, aunque muy relacionados entre sí, los días 11 y 14 de marzo pasados han marcado, de manera considerable, la historia de nuestro país. Por ello, merecen una alusión por nuestra parte. El espantoso atentado terrorista de aquel jueves negro y las elecciones generales ( $\mathrm{y}$ andaluzas) que siguieron, con escasos días de diferencia, constituyen referencias obligadas de reflexión; a partir de ahora, difícilmente las cosas volverán a ser en España, simplemente, "como antes".

Por los inevitables desfases temporales derivados de los plazos de publicación, cuando nuestros lectores reciban este número de la Revista correspondiente al trimestre enero-marzo de 2004, habrán pasado casi 3 meses desde aquellas fechas muy especiales. Dado el inevitable retraso de la aparición del número y los innumerables análisis y comentarios a que ambas fechas han dado lugar, por motivos diferentes, pero muy relacionados, el Consejo de Redacción ha decidido renunciar a redactar sendos comentarios de fondo sobre ambas cuestiones. Para bien y para mal, lo sucedido en esas fechas habrá de seguir siendo objeto de reflexión y, seguramente, lo será más pronto o más tarde en nuestra misma publicación.

En relación con la estremecedora "masacre de los trenes sigue siendo procedente, para los creyentes, orar por los que fallecieron en los atentados; y también sumarnos con nuestro afecto y nuestra solidaridad al dolor de las víctimas supervivientes, de sus familias y seres queridos; de alguna 
manera, todos hemos sido heridos por aquella matanza. Que no les falte nuestro efectivo apoyo.

Tardaremos mucho tiempo en asimilar lo que este atentado y los acontecimientos subsiguientes significan, más allá del contexto puramente español, en este mundo extremadamente polarizado tanto desde el punto de vista del bienestar básico, como religioso, cultural, etc. Porque este nuevo terrorismo relacionado con el fundamentalismo islamista, con manifestaciones tan alarmantes como el sangriento suicidio colectivo de Leganés y las posteriores amenazas en otras vías férreas, plantea graves problemas a la seguridad y a la convivencia pacífica en nuestro mundo. ¿Cómo podremos contribuir nosotros desde el mundo occidental a esta tarea tan urgente como compleja? Es en esa línea en la que nuestra revista quisiera prestar su modesta aportación. El artículo de J. A. Senent que incluimos en este número, es una primera muestra.

Por lo que respecta a las elecciones generales, y al sorprendente vuelco en el mapa político que trajeron consigo, ya se han hecho múltiples comentarios. Más allá de los análisis detallados y de los comentarios sobre las implicaciones políticas de lo sucedido en esta muy especial efeméride electoral, quedará en la memoria de todos la lección de ciudadanía, de normalidad democrática y de reacción colectiva que dio la población, a las pocas horas de una tragedia de la magnitud de la del 11-M.

Ojalá toda la sociedad española, y muy en especial su clase política, estén también a la altura de las circunstancias y acierten en sus iniciativas para luchar adecuadamente contra el terrorismo y contribuir a una verdadera paz mundial, restaurar un clima social de diálogo y negociación desde la conciencia de la pluralidad dentro y fuera de nuestras fronteras, y garantizar -en particular a los más débiles, a los diferentes, a los "de fuera"...- esos mínimos sin los cuales no está salvaguardada la dignidad de la persona humana ni la coexistencia estable entre los pueblos. 


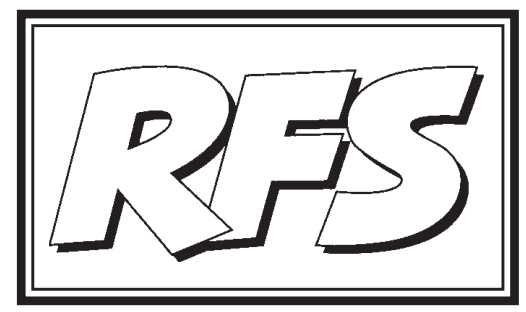

Revista de Fomento Social, 59 (2004), 13-38

\title{
Financiación autonómica: Un reto para el nuevo gobierno
}

\author{
(Palabras clave: Financiación autonómica, Sistema Foral, Autonomía, Solidaridad. \\ KEY WORds: Regional Financing, Autonomous financing, Autonomy, Solidarity)
}

\section{Introducción}

En este artículo editorial queremos abordar un tema actual, técnicamente complejo pero esencialmente político, y, al mismo tiempo, de un hondo contenido ético, que esperamos hacer explícito en las páginas que siguen. Nuestra decisión de volver sobre este tema, del que ya nos hemos ocupado hace unos $a_{n}{ }^{2}{ }^{2}$, surgió a mediados de diciembre de 2003, cuando el gobierno de Cata-

1 Para esta reflexión hemos contado con la ayuda especial de nuestra colega la Profesora Araceli de los Ríos Berjillos, a quien agradecemos su valiosa colaboración.

2 Como recordarán nuestros lectores, ya nos ocupamos de esta cuestión en nuestro editorial: "La solidaridad interterritorial en cuestión", Revista Fomento Social nํ 213 (enero-marzo 1999). 